cấp độ khác nhau đều cho thấy CLDV yếu tố hữu hình là thấp nhất.

Trong số 10 tiểu mục khách hàng đánh giá cao hơn điểm trung bình chung (4,24 điểm) thì có 06 yếu tố thuộc về nhân viên y tế, kết quả này cho thấy bệnh viện đã rất quan tâm đến việc nâng cao chất lượng đội ngũ nhân viên y tế, thực hiên tốt chủ trương của ngành $Y$ tế trong việc đổi mới phong cách, thái độ phục vụ của nhân viên y tế hướng đến sự hài lòng người bệnh.

\section{KẾT LUÂN}

Kết quả nghiên cứu cho thấy người bệnh đánh giá tốt chất lượng dịch vụ tiêm nội nhãn do Bệnh viện Mắt Trung Ương cung cấp. Trong các yểu tố cấu thành nên chất lượng dịch vụ, yếu tố thuộc về NVYT được đánh giá cao từ người bệnh. Bệnh viên cần tiếp tục duy trì các biện pháp tăng cường chất lượng dịch vụ trong thời gian tới.

\section{TÀI LIÊU THAM KHẢO}

1. J. Joseph Cronin JaSAT. Measuring Service Quality: A Reexamination and Extension. Journal of Marketing. 1992;56:55-68.

2. P Tan Le, G Fitzgerald (2014) 'Applying the SERVPERF Scale to Evaluate Quality of Care in Two
Public Hospitals at Khanh Hoa Province, Vietnam'. Asia Pacific Journal of Health Management 9(2).

3. Advances in the Medical Treatment of Diabetic Retinopathy | Diabetes Care [Internet]. [cited 2021 May 12]. Available from: https:// care.diabetesjournals.org/content/32/8/1556.short

4. Multicenter trial of cryotherapy for retinopathy of prematurity. Preliminary results. Cryotherapy for Retinopathy of Prematurity Cooperative Group. Arch Ophthalmol. 1988 Apr;106(4):471-9.

5. Watkins PJ. Retinopathy. BMJ. 2003 Apr 26;326(7395):924-6.

6. Mason JO, Nixon PA, White MF. Intravitreal Injection of Bevacizumab (Avastin) as Adjunctive Treatment of Proliferative Diabetic Retinopathy. American Journal of Ophthalmology. 2006 Oct 1;142(4):685-8.

7. Arab M Ghazi Tabatabaei S Rashidian A Rahimi Forushani A Zarei E (2012) 'The Effect of Service Quality on Patient loyalty a Study of Private Hospitals in Tehran, Iran-annotated-annotated'. Iranian Journal of Public Health, 41 (9) 71-77.

8. The CATT research group (2011) 'Ranibizumab and bevacizumab for Neovascular Aged-Related Macular Degeneration' The New England Journal of Medicine; 364:1897-1908.

9. Rula Al-Damen (2017) "Health Care Service Quality and Its Impact on Patient Satisfaction Case of Al-Bashir Hospital'"'. International Journal of Business and Management, 12 (9).

\title{
KẾT QUẢ ĐIỀU TRI CHỬA SEO MỔ LẤY THAI TẠI BỆNH VIÊ̂N SẢN NHI NGHỆ AN TỪ NĂM 2018 ĐẾN 2020
}

\section{TÓM TẮT}

Mục tiêu: Mô tả kết quả các phương pháp xử trí chửa sẹo mổ lấy thai tại Bệnh viện Sản Nhi Nghệ An từ năm 2018 đến 2020. Đối tượng và phương pháp nghiên cứu: Bệnh nhân được chẩn đoán chửa sẹo mổ lấy thai dưới 12 tuần điêuu trị tại Bệnh viện Sản Nhi Nghệ An từ 1/1/2018 đến 31/12/2020. Nghiên cứu theo phương pháp hồi cứu. Kết quả: có 88 Bênh nhân (BN) được chẩn đoán chửa sẹo mổ lấy thai có 19 ca hút thai đớn thuân, tỷ lệ thành công là $84.2 \%$; 51 bn đặt bóng sau $24 \mathrm{~h}$ hút thai tỷ lệ thành công là $98 \%$. BN điều trị nội khoa có 5 bệnh nhân và tỷ lệ thành công $100 \%$, BN phẫu thuật có 12 bệnh nhân, tỷ lệ thành công $83.3 \%$. Số BN điều trị < 5 ngày là nhóm thực hiện hút thai đơn thuần hoặc hút thai sau đó đặt bóng. Thời gian điều trị $>5$ ngày ở nhóm BN điều trị

\footnotetext{
${ }^{1}$ Bệnh Viện Sản Nhi Nghê An

2 Trường Đai Hoc Y Hà Nôi

Chịu trách nhiệm chính: Trân Thị Ngọc Hà

Email: Drngocha1984@gmail.com

Ngày nhận bài: 5.5.2021

Ngày phản biên khoa hoc: 24.6.2021

Ngày duyệt bài: 7.7.2021
}

MTX kết hợp và bênh nhân phẫu thuât. Kết luân: Phương pháp đặt bóng sau đó hút thai thực hiện tuổi thai 6-7 tuần chiếm $59.1 \%$ tỷ lể thành công $98 \%$, giảm lượng máu mất, giảm chi phí. Phương pháp MTX kết hợ chiếm $5.5 \%$ thành công $100 \%$, thời gian nằm viện kéo dài $>5$ ngày, dài nhất 2 tháng. Phương pháp phẫu thuât chiếm $13.6 \%$, tỷ lệ thành công $83.3 \%$, chủ yếu bệnh nhân đủ con, tuối $>35$ có tuổi thai $>8$ tuân, tăng sinh mạch.

\section{SUMMARY}

RESULT OF METHODS FOR THE TREATMENT OF CESAREAN SECTION SCAR PREGNANCY IN NGHE AN MATERNITYPEDIATRIC HOSPITAL FROM 2018 TO 2020

Objectives: To describe the result of methods for the treatment of pregnancies implanted into a lower uterine segment Cesarean section scar in Nghe An Maternity - Pediatric Hospital from 2018 to 2020. Patients and Methods: This was a retrospective study including women diagnosed with Cesarean section scar pregnancy less than 12 weeks of pregnancy treatment in Nghe An Maternity - Pediatric Hospital from 1st of January, 2018 to 31th of December, 2020. Results: This study included 88 
women who were diagnosed CPS : 19 women was performed simple suction (the success rate is $84.2 \%$ ). 51 women Who had placed balloon then after $24 \mathrm{~h}$ later was performed suction curettage (the success rate is $98 \%$. There were 5 women Who was treatmented by Medical Therapy (the success rate is $100 \%) .12$ Women were treatmented by surgical Therapy (the success rate is $83.3 \%$ ). Treatment time less then 5 days belong to the group that was performed simple suction and was placed balloon then after later performed suction. Treatment time more than 5 days belong to the group that was treatmented by MTX combination therapy and surgical therapy. Conclusions: Used uterine balloon and suction after later was performed 6-7 weeks of pregnancy Method $(59.8 \%)$, with success rate is $98 \%$, reduce the amount of blood loss and cut the cost. MTX combination therapy $(5.5 \%)$, with success rate is $100 \%$, treatment time more than 5 days, the longest of treatment time is 2 months. Surgical Therapy accounted for $13.6 \%$, with success rate is $83.3 \%$, mostly patients with full term, age $>35$, gestational age $>8$ weeks, increased angiogenesis.

\section{I. ĐẶT VẤN ĐỀ}

Chửa sẹo mổ lấy thai là thai làm tổ trong vết sẹo mổ đẻ trên cơ tử cung, trong đó túi thai được bao quanh bởi lớp cơ và mô xơ của vết sẹo. Theo một tổng kết đăng trên tạp chí y khoa của Anh năm 2006, tổng cộng có 18 trường hợp chửa sẹo mổ được ghi nhận trong thời gian từ năm 1978 đến 2002 và 94 trường hợp từ giữa năm 2002 2005. Tỷ lệ chửa sẹo mổ ở việt nam cũng tăng nhiều trong những năm gần đây, có nhiêu đề tài nghiên cứu được ra đời. Nhằm góp phần tổng kết thêm về mô hình bệnh tật chửa sẹo mổ trên cả nước và xem xét thêm các phương pháp điêu trị nên đề tài này được nghiên cứu với mục tiêu: $M o ̂$ tả kêt quả các phương pháp xử trí chửa sẹo mổ lấy thai tại Bệnh viện Sản Nhi Nghệ An từ năm 2018 đên 2020.

\section{II. ĐỐI TƯỢNG VÀ PHƯƠNG PHÁP NGHIÊN CỨU}

2.1. Đối tượng nghiên cứu. Bệnh nhân được chẩn đoán chửa sẹ mổ lấy thai dưới 11 tuần điều trị tại Bệnh viện Sản Nhi Nghệ An từ $1 / 1 / 2018$ đến $31 / 12 / 2020$.

2.1.1. Tiêu chuẩn lựa chọn. CSMLT được chẩn đoán xác định dựa vào một trong các phương pháp:

- Siêu âm đường bụng kết hợp siêu âm đầu dò âm đao chẩn đoán xác định thai làm tổ tại sẹo mổ lấy thai cũ:

+ Buồng tử cung rỗng, không có hình ảnh túi ối trong buồng tử cung.

+ Ông cổ tử cung rỗng, không có hình ảnh túi ối trong ống cổ tử cung.

+ Có hình ảnh túi ối có hoặc không có âm vang thai, tim thai tùy thuộc tuổi thai ở mặt trước eo tử cung.

- Siêu âm có thai và có hình ảnh Doppler mạch máu đi từ vết mổ vào túi thai.

- Chẩn đoán khi phẫu thuật là chửa tại sẹo mổ lấy thai cũ.

- Trường hợp cắt tử cung cả khối có kết quả mô bệnh học gai rau bám vào vùng sẹo mổ eo tử cung.

\subsubsection{Tiêu chuẩn loại trừ:}

- Các trường hợp CSMLT đã được điều trị bằng bất kì một phương pháp nào trước khi vào khoa.

- Chửa ống cổ tử cung.

- Sảy thai dở dang.

- Các trường hợp không đủ thông tin nghiên cứu.

\subsection{Phương pháp nghiên cứu}

2.2.1. Thiết kế nghiên cứu: Nghiên cứu hồi cứu mô tả

Lâp hồ sơ nghiên cứu cho từng bênh nhân từ khi vào viện và theo dõi điêu trị đến khi ra viện.

\subsubsection{Cỡ mẫu}

Cỡ mẫu thuận tiện không xác suất, lấy tất cả các hồ sơ bênh án được chẩn đoán CSMLT và bệnh nhân nhập viện điều trị tại bệnh viện Sản Nhi Nghệ An 1/1/2018 đến 31/12/2020.

\subsubsection{Phương pháp thu thập số liệu}

- Tất cả bệnh nhân có chấn đoán CSMLT được thăm khám, điều trị và theo dõi, ghi lại các số liệu từ khi vào đến khi ra viện dựa vào hồ sơ bệnh án.

+ Tiêu chuẩn thành công: Các trường hợp điều trị bằng 1 phương pháp và:

*Tống xuất hoàn toàn khối thai lạc chỗ ở $\mathrm{SMC}$ mà vẫn bảo tồn được tử cung cho bn.

*Có thể sử dung các phương pháp như bóng chèn, truyền máu để hỗ trợ kiểm soát cầm máu sau khi hút nao.

+ Thất bại: điều trị 1 phương pháp và:

* Phải chuyển phương pháp khác: Tiêm MTX, can thiệp phẫu thuật.

* Ra huyết âm đạo nhiều, ảnh hưởng đến tổng trạng và huyết động học của bệnh nhân hoặc ra huyết lượng nhiều ướt đẫm $>2$ băng vệ sinh dầy trong $1 \mathrm{~h}$, không đáp ứng với các phương pháp khác như hút nạo, bóng chèn cầm máu, truyền máu.

2.4. Xử lý số liệu. Sau khi thu thập đầy đủ thông tin, số liệu được làm sạch, mã hóa và xử lý theo các thuật toán thống kê y học. Phần mềm xử lý SPSS 18.0.

Kết quả nghiên cứu được trình bày dưới dạng phần trăm $(\%)$, giá trị trung bình, so sánh giữa các nhóm bằng test $T$ và khi bình phương (để tính giá trị trung bình và khi bình phương), khi $p<$ 
0,05 thì sự khác biệt có ý nghĩa thống kê.

2.5. Đạo đức trong nghiên cứu. Thông tin của đối tượing nghiên cứu được đảm bảo bí mật.

\section{KẾT QUẢ NGHIÊN CỨU}

Bảng 3.1. Môi liên quan giữa tuổi thai và kêt quả điều trị $(n=88)$

\begin{tabular}{|c|c|c|c|c|}
\hline \multirow{2}{*}{$\begin{array}{c}\text { Tuối thai } \\
\text { (tuân) }\end{array}$} & \multicolumn{2}{|c|}{ Thành công } & \multicolumn{2}{|c|}{ Thất bại } \\
\cline { 2 - 5 } & $\mathbf{n}$ & $\mathbf{\%}$ & $\mathbf{n}$ & $\mathbf{\%}$ \\
\hline$<6$ tuân & 11 & 100 & 0 & 0 \\
\hline
\end{tabular}

\begin{tabular}{|c|c|c|c|c|}
\hline 6-7 tuần & 63 & 95.5 & 3 & 4.5 \\
\hline$\geq 8$ tuần & 8 & 72.7 & 3 & 27.3 \\
\hline Tống & $\mathbf{8 2}$ & $\mathbf{9 3 . 2}$ & $\mathbf{6}$ & $\mathbf{6 . 8}$ \\
\hline
\end{tabular}

Nhân xét: $100 \%$ thành công ở nhóm bệnh nhân có tuổi thai < 6 tuần

Thành công $95 \%$ nhóm bệnh nhân có tuổi thai từ 6 đến 7 tuần

Nhóm bệnh nhân có tuổi thai $>8$ tuần chì thành công $72.7 \%$

Bảng 3.2. Mối liên quan phương pháp điều trị và kêt quả điều trị (n=88)

\begin{tabular}{|c|c|c|c|c|c|c|}
\hline \multirow{2}{*}{ Phương pháp điều trị } & \multicolumn{2}{|c|}{ Thành công } & \multicolumn{2}{|c|}{ Thất bại } & \multirow{2}{*}{$\begin{array}{c}\text { OR } \\
(95 \% \mathrm{CI})\end{array}$} & \multirow{2}{*}{$\mathbf{p}$} \\
\hline & $\mathbf{n}$ & $\%$ & $\mathbf{n}$ & $\%$ & & \\
\hline Hút thai đơn thuân & 16 & 84.2 & 3 & 15.8 & \multirow{8}{*}{$\begin{array}{c}1.1(1.01- \\
1.14)\end{array}$} & \multirow{8}{*}{0.01} \\
\hline Chèn bóng + hút thai & 51 & 98.0 & 1 & 2.0 & & \\
\hline Hút nước ối + MTX toàn thân + MTX tại chố & 1 & 100 & 0 & 0 & & \\
\hline Hút thai+MTX & 2 & 100 & 0 & 0 & & \\
\hline MTX tại chố + toàn thân & 2 & 100 & 0 & 0 & & \\
\hline Mổ mở lấy khối chửa bảo tôn TC & 3 & 100 & 0 & 0 & & \\
\hline Cắt tử cung & 7 & 77.8 & 2 & 22.2 & & \\
\hline Tống & 82 & 93.2 & 6 & 6.8 & & \\
\hline
\end{tabular}

Nhận xét: $84,2 \%$ BN hút thai đơn thuần điều trị thành công. 98\% BN chèn bóng + hút thai điều trị thành công. $77,8 \%$ BN cắt tử cung điêu trị thành công.

Khi so sánh nhóm hút thai (đơn thuần và nhóm đặt bóng kết hợp hút thai) với nhóm lựa chọn phẫu thuật tỷ lệ thành công không có ý nghĩa thống kê với $\mathrm{p}=0.34$ và $\mathrm{OR}=1.13$ (CI $0.87-1.46)$

\section{Bảng 3.3. Thời gian nằm viện}

\begin{tabular}{|c|c|c|c|c|}
\hline \multirow{2}{*}{ Thời gian nằm viện } & \multicolumn{2}{|c|}{$\leq \mathbf{5}$ ngày } & \multicolumn{2}{c|}{$>\mathbf{5}$ ngày } \\
\cline { 2 - 5 } & $\mathbf{n}$ & $\mathbf{\%}$ & $\mathbf{n}$ & $\mathbf{\%}$ \\
\hline Hút thai đơn thuần & 13 & 68.4 & 6 & 31.6 \\
\hline Chèn bóng + hút thai & 40 & 76.9 & 12 & 23.1 \\
\hline Hút nước ối + MTX toàn thân + MTX tại chồ & 0 & 0.0 & 1 & 100.0 \\
\hline Hút thai+MTX & 0 & 0.0 & 2 & 100.0 \\
\hline MTX tại chố + toàn thân & 1 & 50.0 & 1 & 50.0 \\
\hline Mố mở lấy khối chửa bảo tồn tử cung & 0 & 0.0 & 3 & 100.0 \\
\hline Cắt tử cung & 1 & 11.1 & 8 & 88.9 \\
\hline Tống & $\mathbf{5 5}$ & $\mathbf{6 2 . 5}$ & $\mathbf{3 3}$ & $\mathbf{3 7 . 5}$ \\
\hline
\end{tabular}

Nhân xét: BN hút thai đơn thuần và chèn bóng + hút thai phần lớn có thời gian nằm viện $\leq 5$ ngày lẩn lượt $68,4 \%$ và $76,9 \%$.

Tất cả BN Hút nước ối + MTX toàn thân + MTX tại chỗ, Hút thai + MTX, Mổ mở lấy khối chửa bảo tồn tử cung đều nằm viện > 5 ngày.

\section{BÀN LUẬN}

4.1. Mối liên quan tuổi thai và kết quả điêu trị. Số lượng bệnh nhân thuộc nhóm tuổi thai $\geq 8$ tuần chỉ có 11 bệnh nhân nhưng lại có đến 3 bệnh nhân nằm trong nhóm thất bại. Trong khi đó có $11 \mathrm{BN}$ thuộc nhóm < 6 tuần lại không có bệnh nhân nào bị thất bại trong quá trình điều trị. 11 bệnh nhân $\geq 8$ tuần có chỉ định phẫu thuật buộc phải phẫu thuật lại do đánh giá trước mổ và chuẩn bị mổ chưa tốt, mạch máu tăng sinh nhiều, khi mổ chảy máu nhiểu, cộng với kĩ thuật thời kì đầu còn chưa tốt nên sau mồ, chảy máu vết mổ và có trường hợp tổn thương bàng quang. Sau này khi kĩ thuật và đánh giá tốt hơn đã giảm thiểu tỷ lệ thất bai.

Tuổi thai càng lớn thì kích thước túi thai càng to, rau bám rộng, đặc biệt trường hợp thai sống, có tim thai dương tính, dễ gây chảy máu nhiều khi can thiệp vào túi thai. Việc chẩn đoán sớm CSMLT rất có giá trị cho việc điều trị bệnh sau này, do thai nhỏ thì mức độ xâm lấn vết mổ cũ sẽ ít hơn 1.

4.2. Mối liên quan phương pháp điêu trị với tỷ lệ thành công

Nghiên cứu của chúng tôi tập trung vào 4 phương pháp chính:

*Hút thai đơn thuân. Tỷ lê hút thai đơn thuân chiếm tỷ lệ $21.6 \%$ thấp hớn nhiêuu so với 
các nghiên cứu khác. Tỷ lê thành công của phương pháp này là $84.2 \%$, có $15,8 \%$ trường hợp chuyển phẫu thuật do băng huyết trong quá trình thực hiện thủ thuất và theo dõi khối âm vang.

So sánh với Đỗ Thị Ngọc Lan tỷ lệ thành công của phương pháp hút thai đơn thuần là $96,1 \% 2$, Diêm Thị Thanh Thủy là $80 \% 3$. Phương pháp hút thai đơn thuần vẫn là phương pháp dễ chấp nhận vì chi phí thấp, đơn giản, tuy nhiên chỉ nên áp dụng tuổi thai nhỏ hoặc những túi thai có xu hướng về phía buồng tử cung. Đa số tác giả nước ngoài lại khuyến cáo không nên hút thai đơn thuần vì có thể gây ra biến chứng nặng .

Theo Seow 4 nong nạo chỉ nên áp dụng trong một số nhỏ trường hợp khi đã có $\beta$ hCG < $2000 \mathrm{mUI} / \mathrm{ml}$ hoặc sau khi điều trị MTX khối thai không giảm kích thước. Nong nạo không nên là điều trị đầu tiên vì có nguy cơ thủng tử cung và xuất huyết ồ ạt cần phẩu thuật cấp cứu cắt tử cung $50 \%$ vì phần lớn gai rau bám vào cơ tử cung nên khi nạo hút gây thủng tử cung chảy máu nhiều nguy hiểm tới tính mạng người bệnh.

*Đă̆t bóng bằng sond foley và hút thai sau 24h. Bệnh nhân được chỉ định đặt bóng chiếm tỷ lệ cao nhất trong nhóm nghiển cứu( $59.1 \%)$, ghi nhận tỷ lệ thành công là $98 \%$, tương đương với nghiên cứu của tác giả Văn Phụng Thông là $96.8 \%$. Theo tác giả này thì phương pháp đặt sond foley được áp dụng cho trường hợp CSMLT có tuổi thai < 8 tuần, bề dày cơ tử cung $<3 \mathrm{~mm}$, có tăng sinh mạch ít, vừa và không có mạch xuyên thành. Trong quá trình nghiên cứu thây lượng máu mất giảm, thời gian điêu trị ngắn và kinh tế cho bệnh nhân ${ }^{5}$.

*Điêu trị nội khoa bằng MTX (có kết hợp). Trong 88 bênh nhân chỉ có 5 bệnh nhân có sử dụng phương pháp MTX đơn thuần hoăc có kết hợp sử dụng cho thai nhỏ Beta thấp $<1000$, hoặc những trường hợp thai to, tăng sinh mạch nhiều cần diệt phôi và gai rau, sau đó kết hợp các phương pháp khác. Tỷ lệ thành công ghi nhận $100 \%$. Theo Đố Thị Ngọc Lan thành công $97.3 \% 2$. Phần lớn các tác giả nước ngoài khuyến cáo điều trị nội khoa kết hợp là phương pháp khả thi nhất. Theo Timo- trisch tỷ lệ thành công của điều trị nội khoa là $87.7 \%{ }^{6}$.

*Phẫu thuật (bảo tồn tử cung và cắt tử cung). Có 12 bệnh nhân được phẫu thuật, có 3 bệnh nhân được mổ lấy khối chửa và bảo tồn tử cung và 9 bn cắt tử cung. Việc quyết định phẫu thuật thường dựa vào tuổi, số con đã có và đặc biệt là đăc tính của túi thai thường to $>9$ tuần, tăng sinh mạch. Việc phẫu thuật mất máu nhiều hay ít phụ thuộc rất nhiều vào phẫu thuật viên có kinh nghiệm hay không.

Như vậy, việc thực hiện phương pháp nào, tỷ lệ thành công bao nhiêu cần phải có sự đánh giá cá thể hóa, cân nhắc đưa ra phương pháp nào phụ thuộc vào tình trạng cụ thể của bệnh nhân, kĩ thuật phát triển và thành thạo của cơ sở đó. Tuy nhiển cũng cần phải thống nhất ra 1 phác đồ chung để có 1 cái nhìn cục diện, giảm thiểu biến chứng đặc biệt với các cơ sở chưa thành thạo, kinh nghiệm còn non và phẫu thuật chưa tốt.

4.3. Thời gian nằm viện. Thời gian điều trị $\leq 5$ ngày chiếm $62.5 \%$, nhóm này rơi vào những bệnh nhân được thực hiện hút thai đơn thuần hoặc đặt bóng sau đó hút thai. Bệnh nhân sau hút thai được siêu âm và xét nghiệm beta HCG giảm $>80 \%$ sẽ được xuất viện và hẹn tái khám sau 1 tuần.

Những bệnh nhân có thời gian điều trị $>5$ ngày chiếm $37.5 \%$. Chủ yếu là các bệnh nhân được lựa chọn phương pháp điều trị nội khoa và phẩu thuật. Có 18 bệnh nhân vào viện được chỉ định hút thai hoặc chèn bóng hút thai có thời gian điều trị trên 5 ngày là những bệnh nhân có tuổi thai $\sim 7$ tuần, có tim thai, cần phải siêu âm lại để hội chẩn, có những bệnh nhân sau hút bị chảy máy và phải đặt bóng lại sau 24 h rút bóng được siêu âm và xét nghiệm ổn định mới được xuất viện.

Như vậy, thai bám sẹo mổ lấy thai nếu được khám và phát hiện, nhập viện sớm sẽ lựa chọn được phương pháp điệu trị tốt hơn, giảm biến chứng chảy máu và giảm số ngày nằm viện cũng như chi phí điều trị.

\section{KẾT LUÂ̂N}

- Hút thai đơn thuần chiếm $21.6 \%$ tỷ lệ thành công $84.2 \%$, thành công nhóm tuổi thai $<7$ tuân.

- Phương pháp đặt bóng sau đó hút thai thực hiện tuổi thai 6-7 tuần chiếm $59.1 \%$ tỷ lệ thành công $98 \%$, giảm lượng máu mất, giảm chi phí.

- Phương pháp MTX kết hợp chiếm 5.5\% thành công $100 \%$, thời gian nằm viện kéo dài > 5 ngày, dài nhất 2 tháng.

- Phương pháp phẫu thuật chiếm $13.6 \%$, tỷ lệ thành công $83.3 \%$, chủ yếu bệnh nhân đủ con, tuổi > 35 có tuổi thai $>8$ tuần, tăng sinh mạch.

\section{TÀI LIẸU THAM KHẢO}

1. Trưởng Diêm Phượng và Trân Thị Lợi (2013). "Điêu trị thai ngoài tử cung bám ở vết mố cũ tuồ thai dưới 12 tuân tai Bệnh viện Từ Dũ", Tạp chí Y Dược Thành phố Hồ Chí Minh, 17(1), tr 47-55.

2. Đô̂ Thị Ngọc Lan, Đàm Thị Quỵnh Liên, Phạm Duy Duân, Nguyến Thanh Thưy (2012). Tỉnh hình điêuu trị chửa tại sẹo mổ lấy thai cũ tại bệnh 
viện Phụ sản Trung Ương từ tháng 3/2011 đến hết tháng 2/2012, Tap chí phụ sản, 10, 173 - 183.

3. Diêm thi Thanh Thuý (2013), Nghiên cứu chửa seo mổ lấy thai tai bệnh viện phụ sản Hà Nội, Luận vằn tốt nghiệp Bác sỹ̃ chuyên khoa cấp II, Đ̇ại học Y Hà Nôii.

4. K. M. Seow et al. (2004). "Subsequent pregnancy outcome after conservative treatment of a previous cesarean scar pregnancy", Acta Obstet Gynecol Scand, 83 (12), p 1167-72.
5. Văn Phụng Thống (2016), Đặc điểm lâm sàng, cận lâm sàng và đánh giá hiệu quả điều trị thai dưới 8 tuần bám ở seo mổ lấy thai bằng phương pháp đặt foley phối hợp hút thai tại bệnh viện tứ dũ năm 2015. Luận Vằn tốt nghiệp Bác sỹ chuyên khoa II, Trường Đại Hoc Y Dược Cần Thơ, Cần Thơ.

6. Timor-Tritsch IE, Monteagudo A (2012). The diagnosis, treatment, and follow-up of cesarean scar pregnancy. Am J Obstet Gynecol. 2012 Jul;207(1):44.e1-13.

\section{NGHIÊN CỨU HIẸU QUẢ ĐĂT NộI KHÍ QUẢN Có VIDEO HỖ TRƠ CHO BỀNH NHÂN PHẪU THUẦT CộT SỐNG Cổ}

\section{TÓM TẮT}

Muc tiêu: So sánh hiệu quả đặt nội khí quản có video hỗ trợ với lưỡi đèn Macintosh cho bệnh nhân phẫu thuật cột sống cổ và tác dụng không mong muốn của phương pháp này. Phương pháp nghiên cứu: Trên 160 bệnh nhân phẫu thuât côt sống cô gồm nhóm I dùng đèn đặt NKQ có Video hỗ trợ $(n=$ $80)$ và nhóm II đăt NKQ bằng đèn Macintosh $(n=80)$. Theo dõ̃i tỷ lệ thành công lần 1, số bệnh nhân cần ấn sụn nhẫn, số bệnh cần phải ngửa cổ, Cormack và Lehane, POGO, thời gian đặt nội khí quản tính theo giây và theo dõi đau họng, khàn tiếng sau mổ. Kết quả: Số bệnh nhân cần ấn sụn nhẫn, cẫn ngửa cổ của nhóm I ít hơn của nhóm II tỷ lê POGO của nhóm I cao hơn nhóm II với $p<0,05$, độ Cormack và Lehane nhóm I thấp hơn nhóm II $\mathrm{p}<0,05$, thời gian đặt NKQ của nhóm I nhanh hơn nhóm II với $p<0,05$, tỷ lệ thành công của nhóm I cao hơn nhóm II với $p<0,05$. Đau họng, khàn tiếng sau mổ của nhóm I thấp hơn của nhóm II với $p<0,05$. Kết luận: Số bệnh nhân cần ấn sụn nhẫn, ngửa cổ khi đặt NKQ của nhóm I thấp hơn của nhóm II với $p<0,05_{h}$ tỷ lệ POGO của nhóm I cao hơn nhóm II, Video hố trơ nhìn thanh môn rõ hơn đèn soi thanh quản Macintosh vì độ Cormack và Lehane nhóm I thấp hơn nhóm II ( $p$ < $0,05)$, tỷ lệ đặt thành công lần đâu của nhóm I cao hơn của nhóm II với $p<0,05$, thời gian đă̆t NKQ của nhóm I nhanh hơn nhóm II có sự khác biệt với $p$ < 0,05 và tỷ lệ đau họng, khàn tiếng sau mổ của nhóm I thấp hơn của nhóm II với $p<0,05$.

Tư khóa: Đặt NKQ có Video hỗ trợ, Video laryngoscopy.

\section{SUMMARY \\ STUDY THE EFFICACY OF ASSISTED INTUBATION FOR THE PATIENS WITH}

\footnotetext{
*Bệnh viện đa khoa Nông nghiệp

**Bênh viên Viết Đúrc

Chịu trách nhiệm chính: Dương Anh Khoa

Email: duonganhkhoa1971@gmail.com

Ngày nhận bài: 7.5.2021

Ngày phản biên khoa hoc: 28.6.2021

Ngày duyệt bài: 8.7.2021
}

\section{Dương Anh Khoa*, Nguyễn Quốc Kính**}

\section{CERVICAL SPINAL SURGERY}

Objective: To Compare the efficacy of assisted intubation with the Macintosh in the patients with cervical spinal surgery and complication this methods. Methods: In the 160 patients with cervical spinal surgery included group I using intubation with assisted video $(\mathrm{n}=80)$ and group II with Macintosh $(n=80)$. Follow up the first time success ratio, the Cormack and Lehane, POGO, patients should be cartilage ring pressed down, patient should be put the neck up; the times (seconds) of the intubation, sore throat, hoarse voice after surgery. Results: the number of patients needed to be pressed cartilage ring down, to be put the neck up in the group I less than that in the group II; the POGO in group $\mathrm{I}$ is higher than that in group II ( $p<0.05)$; Cormack and Lehane levels in group I were lower than that in group II with $p<0.05$; Intubation time: group I was faster than group II $(\mathrm{p}<0.05)$; The success rate of group I was higher than that of group II with statistical significance $\mathrm{p}<0.05$; the rate of sore throat, hoarseness after surgery of group I was lower than that of group II with $\mathrm{p}<0.05$. Conclusions: the number of patients needed to be pressed cartilage ring down, to be put the neck up in the group I less than that in the group II $(p<0.05)$, the POGO in group I is better than that in group II; Intubation with video assissted: Cormack and Lehane levels in group I were lower than that in group II with $p<0.05$. The first successful intubated: group I was higher than that of group II ( $p<0.05)$; Intubation time: group I was faster than group II $(p<0.05)$; the rate of sore throat, hoarseness after surgery of group I was lower than that of group II with $p<0.05$.

Key words: Intubation with video assissted, Video laryngoscopy

\section{I. ĐặT VẤN ĐỀ}

Trước đây đèn Macintosh là tiêu chuẩn vàng để đặt NKQ cho phẫu thuật cột sống cổ. Những ca NKQ khó thì rất khó thực hiện và tỷ lệ đặt nội khí quản thất bại cao, dễ gâyy tai biến chấn thương răng miệng 0,5 đến $7 \%$ [5], có thể gây loét sụn nhẫn do ống nội khí quản là $0,005 \%$ 